\title{
LAS ACCIONES DE INCONSTITUCIONALIDAD EN LA CONSTITUCIÓN MEXICANA: BALANCE EMPÍRICO DE DOCE AÑOS DE EJERCICIO
}

\section{UNCONSTITUNALITY ACTIONS IN MEXICAN CONSTITUTION: EMPIRICAL BALANCE OF TWELVE YEARS OF EXERCISE}

\author{
Sergio LÓPEZ-AYLLÓN \\ Florencio VALLADARES
}

RESUMEN: El 31 de diciembre de 2008 se cumplieron 13 años desde que la reforma constitucional introdujo dos nuevos mecanismos de control constitucional: la "controversia constitucional" y la "acción de inconstitucionalidad". Este artículo se aleja de la perspectiva doctrinal y realiza un balance empírico de esta institución a partir de una base de datos de 301 acciones resueltas por la Suprema Corte de Justicia entre 1995 y 2007. El análisis muestra que durante los primeros años las acciones que se interpusieron fueron relativamente pocas y principalmente en materia electoral. Con el tiempo el número de acciones se ha incrementado significativamente y también se ha diversificado su materia e impacto, como resultado de un litigio constitucional cada vez más complejo y diverso.

Palabras clave: acción de inconstitucionalidad; control constitucional; Suprema Corte de Justicia
ABSTRACT: On December 31 2008, were met 13 years of one of the most important constitutional reforms to the justice system in Mexico, which introduced two new constitutional control mechanisms: the controversias constitucioniales and the acción de inconstitucionalidad. This article deviates from theoretical perspective and place an empirical assessment of this institution from a database of 301 actions settled by the $\mathrm{Su}$ preme Court between 1995 and 2007. The analysis shows that during the early years the acciones that were interposed were relatively few and mainly in electoral matters. With time the number of acciones has been increased significantly and also it has been diversified to its matter and impact, as a result of complex and more diverse constitutional conflicts.

Descriptors: constitutional procedure; constitutional control; Supreme Court of Justice 


\section{INTRODUCCIÓN}

El 31 de diciembre de 1994 se publicó en el Diario Oficial de la Federación un decreto que reformó diversos artículos de la Constitución Política de los Estados Unidos Mexicanos en relación con el sistema de impartición de justicia. Esta reforma es generalmente considerada como un punto de inflexión en el diseño del Poder Judicial federal y el sistema de control de la constitucionalidad en México. De manera específica, se estableció una nueva composición de la Suprema Corte de Justicia y se le atribuyeron nuevas facultades que la configuraron prácticamente como un tribunal constitucional. Igualmente se estableció el Consejo de la Judicatura Federal y se creó una carrera judicial formal. ${ }^{1}$

Entre las nuevas facultades de la Suprema Corte de Justicia la reforma estableció dos nuevos mecanismos de control de constitucionalidad: ${ }^{2}$ la "controversia constitucional" y la "acción abstracta de inconstitucionalidad" (en adelante "acción de inconstitucionalidad"). La introducción de estas figuras tenía la intención expresa de otorgar a la Suprema Corte Mexicana una función de tribunal constitucional, es decir, "dotarla de atribuciones para controlar la constitucionalidad de cualquier acto de autoridad, permitir que los órganos del Estado defendieran sus competencias, facultar el planteamiento de cuestiones de constitucionalidad de tipo abstracto, y darle a las resoluciones efectos generales". 3

Desde entonces diversos autores han estudiado, principalmente desde una perspectiva doctrinal, estas dos figuras, en particular la acción de inconstitucionalidad. Se han analizado sus alcances y se han sugerido diversas reformas para perfeccionar su funcionamiento. No obstante lo anterior, prácticamente no existen estudios que proporcionen información

1 Sobre esta reforma véase, Fix-Fierro, Héctor, "La reforma judicial en México: ¿De dónde viene? ¿Hacia dónde va?”, Reforma Judicial. Revista Mexicana de Justicia, núm. 2, julio-diciembre de 2003, pp. 259 y ss.; Cossío Díaz, José Ramón, La teoría constitucional de la Suprema Corte de Justicia, México, Fontamara, 2002, pp. 62-70; Caballero, José Antonio et al., Libro blanco de la Reforma Judicial. Una agenda para la justicia en México, México, Suprema Corte de Justicia de la Nación, 2006, pp. 67-88.

2 Véase Fix-Fierro, Héctor, "La defensa de la constitucionalidad en la reforma judicial de 1994", Cuadernos Constitucionales México-Centroamérica, núm. 19, 1996, pp. 41-57.

3 Cossío Diaz, op. cit., supra, nota 1, p. 64. 
empírica para valorar el funcionamiento que en la práctica ha tenido este medio de control constitucional.

Este artículo presenta una síntesis y actualiza los principales resultados de un estudio más amplio que realizó un balance de las acciones de inconstitucionalidad luego de 12 años de operar en el sistema jurídico mexicano. ${ }^{4}$ Precisamos que este trabajo no es estudio doctrinal, sino que se concentra en el análisis de los datos de las controversias resueltas por la Suprema Corte de Justicia entre 1995 y 2007. Como se documenta adelante, del análisis se desprende que aunque durante varios años las acciones de inconstitucionalidad que se interpusieron fueron relativamente pocas y se utilizaron mayormente en materia electoral, con el tiempo su número se ha incrementado significativamente y también se ha diversificado su materia e impacto como resultado de un litigio constitucional cada vez más complejo y diverso. Los datos muestran con un nivel suficiente de confianza que las acciones de inconstitucionalidad han cumplido su función de control de la constitucionalidad con una eficacia aceptable y que resulta previsible que el número de acciones de inconstitucionalidad se incrementará en los próximos años. Consideramos que este estudio puede contribuir a valorar los posibles impactos de algunas de las reformas propuestas en la materia, en particular luego de la publicación del Libro blanco de la reforma judicial ${ }^{5}$ y de los trabajos de la Comisión Ejecutiva de Negociación y Construcción de Acuerdos del Congreso de la Unión para la Reforma del Estado (CENCA) en materia de reforma judicial. ${ }^{6}$

Aunque como se ha dicho, este artículo no es un estudio doctrinal sobre las acciones de inconstitucionalidad, en beneficio de los lectores se expondrá de manera muy sucinta en qué consisten, remitiéndolos a la vasta bibliografía especializada que existe en la materia. ${ }^{7}$

4 Véase Valladares Zambrano, Florencio, Las acciones de inconstitucionalidad: un análisis empírico 1995-2006, tesis profesional de licenciatura en derecho, Centro de Investigación y Docencia Económica, marzo de 2007, p. 253 (director de tesis: Sergio López-Ayllón).

5 Véase Caballero et al., op. cit., nota 1, passim.

6 Sobre esta cuestión puede consultarse la página electrónica http://www.senado.gob.mx/comisiones/LX/cenca/.

7 Véase Fix-Fierro, "La reforma judicial de 1994 y las acciones de inconstitucionalidad", Revista del Instituto de Documentación e Investigación Jurídicas de la Facultad de Derecho de la Universidad Panamericana, vol. 13, número especial, 1995; Fix Zamu- 
La acción de inconstitucionalidad es un mecanismo de control constitucional que se interpone ante la Suprema Corte de Justicia de la Nación con la finalidad de que ésta examine la constitucionalidad de una ley o un tratado internacional. Se trata de un mecanismo de control constitucional que no implica la existencia de un agravio o interés específico, sino que se plantea como una revisión en abstracto de la constitucionalidad de una ley o tratado internacional. La siguiente tabla sintetiza los órganos legitimados para interponerla:

Tabla 1. Órganos legitimados para interponer acciones de inconstitucionalidad

\begin{tabular}{|l|l|}
\hline \multicolumn{1}{|c|}{ Órganos facultados } & \multicolumn{1}{|c|}{ Tipo de ley } \\
\hline $\begin{array}{l}\text { Minorías }(33 \%) \text { de los órganos legislativos, } \\
\text { estatales o federal }\end{array}$ & $\begin{array}{l}\text { Leyes expedidas por los órganos legislativos } \\
\text { correspondientes }\end{array}$ \\
\hline Procurador General de la República & Cualquier ley federal o estatal \\
\hline Partidos políticos con registro federal o estatal & Leyes electorales \\
\hline $\begin{array}{l}\text { Órganos de protección de derechos humanos } \\
\text { estatales o federal }\end{array}$ & Leyes que versen sobre derechos humanos \\
\hline
\end{tabular}

La jurisprudencia de la Suprema Corte de Justicia ha establecido las siguientes características de la acción de inconstitucionalidad:

- Se promueve para alegar la contradicción entre una norma impugnada y una de la Constitución Política de los Estados Unidos Mexicanos.

dio, Héctor y Cossío Díaz, José Ramón, El Poder Judicial en el ordenamiento mexicano, México, Fondo de Cultura Económica, 1996; Corzo, Edgar, La cuestión de inconstitucionalidad, Madrid, CEPC, 1998; Fix-Zamudio Héctor y Valencia, Salvador, Derecho constitucional mexicano y comparado, México, Porrúa, 1999; Brage Camazano, Joaquín, La acción de inconstitucionalidad, México, UNAM, 2000; Reyes Reyes, Pablo Enrique, La acción de inconstitucionalidad, México, Oxford University Press, 2000; Huerta Ochoa, Carla, Mecanismos constitucionales para el control del poder político, 2a. ed., México, UNAM, 2001; Reyes Retana, Ismael, "Apuntes sobre los efectos de las resoluciones en controversias constitucionales y acciones de inconstitucionalidad", Jurípolis, año 3, vol. 1, 2003; Huerta Ochoa, Carla, "La acción de inconstitucionalidad como control abstracto de conflictos normativos", Boletín Mexicano de Derecho Comparado, año XXXVI, núm. 108, 2003; Poder Judicial de la Federación, Suprema Corte de Justicia de la Nación, ¿Qué son las acciones de inconstitucionalidad?, y 2a. ed., México, SCJN, 2004. 
- Puede ser promovida por el procurador general de la República, los partidos políticos y un mínimo de $33 \%$ de los integrantes del órgano legislativo que haya expedido la norma.

- Supone una solicitud para que la Suprema Corte de Justicia de la Nación analice en abstracto la constitucionalidad de una norma.

- Se trata de un procedimiento.

- Puede interponerse para combatir cualquier tipo de normas (sic).

- Sólo procede por lo que respecta a normas generales.

- La sentencia tendrá efectos generales sólo si es aprobada por cuando menos ocho ministros. ${ }^{8}$

Una resolución de la Corte puede declarar con relación a la norma impugnada su constitucionalidad (validez), su inconstitucionalidad (invalidez), su invalidez parcial, el sobreseimiento o la desestimación (cuando la votación no alcanza los ocho votos necesarios y por ello la norma no se declara inconstitucional).

\section{MetodologíA}

El estudio comprende las acciones de inconstitucionalidad resueltas en el periodo que va de enero de 1995 a diciembre de 2007. Cuando se inició la investigación se carecía de datos oficiales que permitieran conocer con certeza el universo total de acciones de inconstitucionalidad presentadas y resueltas ante la Suprema Corte de Justicia de la Nación. Por ello, y para construir la muestra, se procedió a buscar los asuntos digitalizados en la Suprema Corte de Justicia de la Nación o en Internet a través del Diario Oficial de la Federación. Luego de esta búsqueda se identificaron 301 casos resueltos. Aunque no constituyen el total de las acciones de inconstitucionalidad resueltas durante el periodo de estudio ni - como hubiera sido deseable - se tuvo acceso directo al expediente, se construyó una muestra suficientemente representativa que permite asegurar conclusiones robustas y válidas. ${ }^{9}$

8 Tesis P7J 71/2000, Semanario Judicial de la Federación y su Gaceta, novena época, t. XII, agosto de 2000, p. 965. La Suprema Corte Mexicana se integra por $11 \mathrm{mi}-$ nistros.

9 De acuerdo con datos proporcionados por la Dirección General de Planeación de lo Jurídico de la Suprema Corte de Justicia de la Nación de enero de 1995 a diciembre 
Para construir la base de datos se realizó un estudio exhaustivo del procedimiento y las resoluciones a partir del cual se identificaron 63 variables. Una vez elegidas las variables y concluida la base de datos, ${ }^{10} \mathrm{se}$ procedió al análisis e interpretación de los datos. Los resultados que se exponen a continuación son sólo una muestra de los resultados obtenidos, pues la base de datos permite muchas otras posibilidades de explotación. Para facilitar la exposición se utilizan una serie de gráficas y tablas comparativas, todas elaboradas a partir de la base de datos, salvo que se indique de manera expresa otra fuente.

\section{ANÁLISIS}

El análisis que presentamos se estructura a partir de una selección de tópicos, a saber: órganos legitimados; acumulación; materias; sentido de las resoluciones; votación y tiempos de resolución. Para cada apartado se construyeron distintos indicadores que permiten mostrar los principales resultados.

\section{1. Órganos legitimados}

Este apartado tiene por objeto conocer quiénes son los órganos legitimados que, en la práctica, interponen con mayor frecuencia acciones de inconstitucionalidad. La siguiente gráfica muestra el número de acciones de inconstitucionalidad presentadas por año y por tipo de órgano legitimado para interponerla. Para facilitar la presentación de los resultados, éstos se agruparon en los cuatro grupos siguientes: 1) partidos políticos (federales y estatales); 2) órganos legislativos estatales (legislaturas loca-

de 2007 ingresaron 488 acciones de inconstitucionalidad, de las cuales se habían resuelto 345 hasta esa misma fecha. Sin embargo, entre esas 345 se encuentran 29 que fueron desechadas en el auto admisorio, por lo que el número de "resueltas" debe reducirse a 316. La muestra que se construyó para este estudio consta de 301 acciones resueltas, por lo que únicamente no se consideraron 15 acciones que obran en los registros de la SCJN. Agradecemos a las licenciadas Mara Pérez Gómez y Jacqueline Martínez su amabilidad y colaboración para corroborar la información.

10 Las limitaciones de espacio propias de esta publicación nos impidieron anexar la lista de variables y otros anexos relevantes. Sin embargo, éstos pueden ser consultados en la siguiente dirección electrónica: http://www.cide.edu/investigador/sitios.php?IdInvestigador $=1079$. 
les y Asamblea Legislativa del Distrito Federal); 3) procurador general de la República, y 4) órganos legislativos federales (Cámara de Diputados y Cámara de Senadores). ${ }^{11}$

Gráfica 1. Acciones de inconstitucionalidad por órganos legitimados
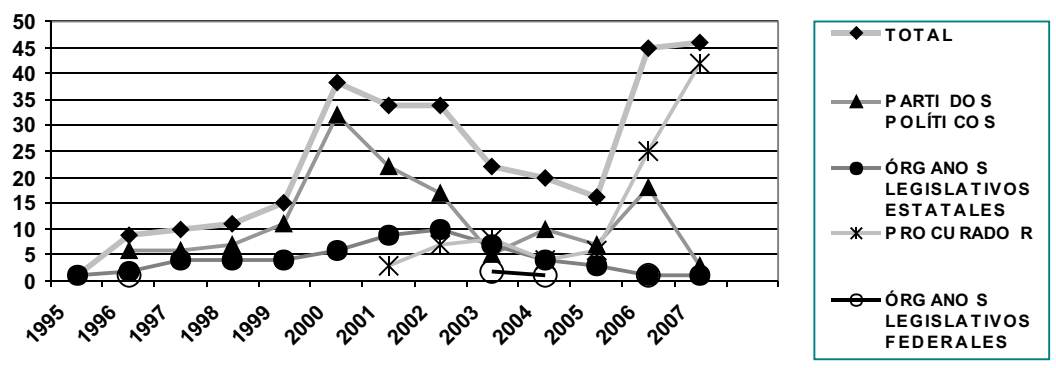

FUENTE: elaboración propia con datos tomados de los expedientes analizados.

De la gráfica anterior se observa que los órganos legislativos federales han sido los usuarios menos activos. El procurador general de la Repú-

11 No se incluye en el análisis a la Comisión Nacional de los Derechos Humanos y los organismos de protección de los derechos humanos de las diferentes entidades federativas, ambos legitimados para interponer acciones mediante reforma constitucional de septiembre de 2006, pues dentro de las fechas que incluye este estudio no se resolvió ningún asunto interpuesto por estos órganos. En mayo de 2007 la Comisión Nacional de los Derechos Humanos interpuso la acción de inconstitucionalidad en contra del Decreto por el que se reforma el Código Penal para el Distrito Federal y se adiciona la Ley de Salud para el Distrito Federal expedido por la Asamblea Legislativa del Distrito Federal en el cual se despenalizan la interrupción del embarazo para las mujeres que lo hagan y las personas que las auxilien, siempre y cuando la interrupción del embarazo se realice antes de que se cumplan las 12 semanas de gestación. Esta acción fue resuelta en agosto de 2008, por lo cual no forma parte de la muestra con la que se elaboró este estudio. Más recientemente la Comisión de Derechos Humanos de Puebla interpuso una acción de inconstitucionalidad en contra de las reformas a la Ley de Transparencia y Acceso a la Información de ese Estado. La resolución del asunto está pendiente. 
blica presentó actividad en la materia hasta 2001, pero el número de acciones interpuestas por este órgano se ha incrementado significativamente en particular desde 2006. Los órganos legislativos estatales han promovido relativamente pocas acciones pero de manera constante, aunque su participación disminuyó en 2007. Esta misma situación se observa en los partidos políticos, quienes son los actores que, sin embargo, han interpuesto el mayor número de acciones a pesar de haber obtenido su legitimación hasta 1996. A continuación procederemos a un análisis más detallado del comportamiento de cada uno de los grupos.

\section{A. Órganos legislativos federales}

Entre junio de 1995 y diciembre de 2007 el Congreso de la Unión aprobó o reformó 703 leyes. ${ }^{12}$ La Cámara de Diputados promovió sólo cuatro acciones de inconstitucionalidad: una en 1996, dos en 2003 y una en 2004. Por su parte la Cámara de Senadores lo hizo en una ocasión en 2006. Claramente la actividad del Congreso en conjunto y de cada una de las Cámaras en particular ha sido mínima y discontinua, particularmente si se le compara con otros actores (por ejemplo, la PGR interpuso 95 acciones en el mismo periodo).

Así, las cámaras son órganos que prácticamente no han utilizado la acción de inconstitucionalidad. Ello sugiere bien que las minorías parlamentarias han decidido no utilizar este mecanismo, o bien que el porcentaje que se requiere para utilizarlo $(33 \%)^{13}$ es demasiado alto considerando la configuración del Congreso y de las minorías parlamentarias en los últimos años, lo que hace que este pueda utilizarse sólo en condiciones excepcionales. ${ }^{14}$

12 Recuento propio elaborado con datos del Diario Oficial de la Federación. El anexo respectivo puede consultarse en la siguiente dirección electrónica http://www.cide.edu/ investigador/sitios.php? IdInvestigador $=1079$.

13 La Constitución establece que las acciones de inconstitucionalidad pueden ser promovidas por el equivalente al 33\% de la Cámara de Diputados o de la Cámara de Senadores en contra de leyes federales o del Distrito Federal expedida por aquél. En el caso del Senado se requiere el mismo porcentaje para promover en contra de tratados internacionales celebrados por el Estado mexicano.

14 Este es claramente el caso de la acción de inconstitucionalidad promovida por senadores de varios partidos (PRI, PAN, PRD) en contra de las reformas a la Ley Federal de Radio y Televisión. 
Un aspecto que merece atención especial es el relativo a los tratados internacionales. El Senado se encuentra legitimado de manera exclusiva para impugnarlos, sin embargo en ningún caso lo ha hecho, a pesar de que entre 1996 y 2005 se aprobaron aproximadamente $355^{15}$ instrumentos internacionales, con los más variados temas: medio ambiente, comercio exterior, cooperación técnica y científica, telecomunicaciones, turismo, fiscal, intercambio cultural, derechos humanos, extradición y asistencia mutua en materia penal, entre otros.

Al respecto, podemos suponer que existe de hecho una especie de control constitucional previo relacionado con la aprobación de los tratados internacionales. Por un lado está la Presidencia de la República, a través de la Secretaría de Relaciones Exteriores y la Consejería Jurídica del Ejecutivo Federal, que son las instancias encargadas, entre otras funciones, de examinar la constitucionalidad de los tratados internacionales que suscribe el Ejecutivo; y por otro está el propio Senado de la República que realiza un segundo análisis de constitucionalidad a través de los comisiones respectivas antes de ser aprobados por el Pleno de ese órgano. Esto explicaría por qué, en la práctica, existan pocas probabilidades de que una minoría de $33 \%$ de senadores impugne la constitucionalidad de un tratado mediante una acción de inconstitucionalidad.

\section{B. Procurador general de la República}

El procurador general de la República ha promovido 95 acciones de inconstitucionalidad entre 2001 y 2007 conforme a la siguiente secuencia:

Tabla 2. Número de acciones interpuestas por el procurador general

\begin{tabular}{|c|c|}
\hline Año & Número de acciones \\
\hline $1995-2000$ & 0 \\
\hline 2001 & 3 \\
\hline 2002 & 7 \\
\hline 2003 & 8 \\
\hline 2004 & 4 \\
\hline 2005 & 6 \\
\hline
\end{tabular}

15 México, Senado de la República. Tratados celebrados por México 1823-2005, SRE-Senado de la República, versión digital. 


\begin{tabular}{|c|c|}
\hline 2006 & 25 \\
\hline 2007 & 42 \\
\hline Total & 95 \\
\hline
\end{tabular}

FUENTE: elaboración propia con datos tomados de los expedientes analizados.

Como puede apreciarse, existe un incremento significativo de la actividad del procurador a partir de 2006, cabe entonces preguntarse qué factores incidieron en este notable cambio de política. Proponemos como hipótesis que esto puede explicarse por la especialización institucional del litigio constitucional dentro de la PGR, la relativa autonomía de los procuradores, la creciente complejidad de la acción gubernamental debido a la fragmentación política, así como la gestión y el interés específico de los diferentes procuradores con relación al control de la constitucionalidad.

En efecto, de diciembre de 1994 a diciembre de 2007, la Procuraduría General de la República tuvo cinco titulares. La siguiente tabla muestra la dinámica en materia de acciones de inconstitucionalidad:

Tabla 3. Dinámica de los procuradores en relación con la interposición de las acciones de inconstitucionalidad

\begin{tabular}{|l|l|c|}
\hline \multicolumn{1}{|c|}{ Titulares } & \multicolumn{1}{|c|}{ Periodo } & $\begin{array}{c}\text { Número } \\
\text { de acciones }\end{array}$ \\
\hline $\begin{array}{l}\text { Fernando Antonio Lozano } \\
\text { Gracia }\end{array}$ & $\begin{array}{l}\text { 10. de diciembre de 1994 al 1o. de diciembre } \\
1996 \\
\text { (dos años) }\end{array}$ & 0 \\
\hline Jorge Madrazo Cuéllar & $\begin{array}{l}\text { 2 de diciembre de 1996 al 30 de noviembre } \\
\text { de 2000 } \\
\text { (cuatro años) }\end{array}$ & 0 \\
\hline Rafael Macedo de la Concha & $\begin{array}{l}\text { 1o. diciembre de 2000 al27 de abril de 2005 } \\
\text { (cuatro años, cuatro meses) }\end{array}$ & 23 \\
\hline $\begin{array}{l}\text { Daniel Francisco Cabeza de } \\
\text { Vaca Hernández }\end{array}$ & $\begin{array}{l}\text { 28 de abril de 2005 al 30 de noviembre de } \\
\text { 2006 } \\
\text { (un año siete meses) }\end{array}$ & 30 \\
\hline Eduardo Medina Mora Icaza & $\begin{array}{l}\text { 6 de diciembre de 2006 al 31 de diciembre } \\
\text { de 2007 } \\
\text { (un año) }\end{array}$ & 42 \\
\hline
\end{tabular}

FUENTE: Elaboración propia con datos tomados de la página electrónica: http://www.pgr.gob.mx/. 
Como puede apreciarse, las gestiones de Rafael Macedo de la Concha, Daniel Francisco Cabeza de Vaca y Eduardo Medina Mora incrementaron el número de acciones interpuestas. Sin embargo, destaca la gestión de Cabeza de Vaca pues, en un año y medio interpuso más acciones que su antecesor en cuatro años. Además, al correlacionar dicho número de impugnaciones con el sentido en que se resolvieron, la mayoría de las acciones resultaron fundadas, modificando la tendencia mostrada previamente. ${ }^{16}$ Resulta interesante destacar que el ex procurador Cabeza de Vaca se había desempeñado previamente como Consejero Jurídico del Ejecutivo Federal, ${ }^{17}$ y que el ex subprocurador de Asuntos Internacionales, Javier Laynez Potisek, responsable orgánicamente del área jurídica de la PGR, fue también por muchos años consejero jurídico adjunto y es un conocedor profundo del sistema de control constitucional. ${ }^{18}$

Así, podemos suponer que la especialización, experiencia y conocimiento técnico constitucional de los funcionarios se convierten en elementos clave para el desarrollo de una política pública explícita orientada a la promoción de las acciones de inconstitucionalidad con resultados generalmente favorables. El argumento anterior se fortalece si observamos que la actuación del procurador Medina Mora se ha concentrado en la materia fiscal, pues $93 \%$ de las 42 acciones presentadas se han dado en esta materia. Ello es relevante si se considera que durante la gestión del ex procurador Cabeza de Vaca se generaron importantes precedentes en esta materia.

En todo caso, lo relevante es que el procurador ha asumido con mayor claridad su papel de garante de la Constitución ${ }^{19}$ y que estructuralmente

16 Antes de la gestión del ex procurador Daniel Francisco Cabeza de Vaca, la efectividad de la Procuraduría General de la República era de $26.08 \%$ de acciones fundadas o parcialmente fundadas, y $73.92 \%$ de acciones declaradas infundadas, sobreseídas, desechadas o desestimadas. Al terminar su gestión, la efectividad se incrementó y se invirtió, al ser el $93.33 \%$ de las acciones fundadas o parcialmente fundadas, y sólo el $6.67 \%$ de las acciones infundadas.

17 De noviembre de 2004 hasta el 27 de abril de 2005. Fuente http://fox.presiden cia.gob.mx/gabinete/? contenido $=15044$.

18 La trayectoria profesional de Javier Laynez, actualmente procurador fiscal de la Federación, véase El Mundo del Abogado, año 11, núm. 112, agosto de 2008, pp. 12-17.

19 De conformidad con el apartado A del artículo 102 constitucional, el procurador general de la República tiene entre sus atribuciones la de intervenir personalmente en las controversias y acciones de inconstitucionalidad. 
la Procuraduría tiene mayores capacidades institucionales en materia de control constitucional.

\section{C. Órganos legislativos locales}

Las legislaturas estatales tienen un nivel relativamente constante de interposición de acciones de inconstitucionalidad y, como se verá más adelante, han recurrido las materias más variadas. Así, los órganos legislativos estatales han promovido acciones de inconstitucionalidad en 56 ocasiones conforme a la siguiente secuencia:

Tabla 4. Acciones de inconstitucionalidad promovidas por los órganos legislativos estatales por año

\begin{tabular}{|l|c|c|c|c|c|c|c|c|c|c|c|c|c|c|}
\hline Año & 1995 & 1996 & 1997 & 1998 & 1999 & 2000 & 2001 & 2002 & 2003 & 2004 & 2005 & 2006 & 2007 & Total \\
\hline Número & 1 & 2 & 4 & 4 & 4 & 6 & 9 & 10 & 7 & 4 & 3 & 1 & 1 & 56 \\
\hline
\end{tabular}

FUENTE: elaboración propia con datos tomados de los expedientes analizados.

La frecuencia con que ha impugnado cada legislatura es la siguiente:

Tabla 5. Acciones de inconstitucionalidad promovidas por los órganos legislativos estatales

\begin{tabular}{|l|c|l|c|l|l|c|}
\hline Legislatura & D F & $\begin{array}{l}\text { Aguascalientes, } \\
\text { Chihuahua, } \\
\text { Nuevo León, } \\
\text { Yucatán }\end{array}$ & $\begin{array}{l}\text { Sinaloa, } \\
\text { Sonora }\end{array}$ & $\begin{array}{l}\text { Baja California } \\
\text { Sur, } \\
\text { Colima, } \\
\text { Durango, } \\
\text { Morelos, } \\
\text { Tabasco, } \\
\text { Veracruz }\end{array}$ & $\begin{array}{l}\text { Baja California } \\
\text { Campeche, } \\
\text { Chiapas, } \\
\text { Coahuila, }\end{array}$ & Total \\
& & & & & $\begin{array}{l}\text { Hidalgo, } \\
\text { Jalisco, } \\
\text { México, } \\
\text { Michoacán, } \\
\text { Querétaro, } \\
\text { San Luis Potosí }\end{array}$ & \\
& & & & & 1 & 19 \\
\hline Número & 8 & 5 & 3 & 2 & 19 & 1 \\
\hline
\end{tabular}

FUENTE: elaboración propia con datos tomados de los expedientes analizados.

Como puede observarse, 16 legislaturas han interpuesto acciones de inconstitucionalidad en una o dos ocasiones durante el periodo observa- 
do. Sólo cuatro legislaturas lo han hecho en cinco ocasiones y la Asamblea Legislativa del DF en ocho. Por otro lado, nueve legislaturas nunca han utilizado este mecanismo (Guanajuato, Guerrero, Nayarit, Oaxaca, Puebla, Quintana Roo, Tamaulipas, Tlaxcala y Zacatecas). ${ }^{20}$ No contamos con datos que permitan por el momento establecer alguna hipótesis explicativa de este comportamiento.

\section{Los partidos políticos}

Son los actores que con más frecuencia y constancia han utilizado las acciones de inconstitucionalidad (144 casos). En otras palabras, la materia electoral es la que genera un mayor número de acciones. La siguiente tabla presenta la actividad por año.

Tabla 6. Número de acciones presentadas por los partidos políticos

\begin{tabular}{|l|c|c|c|c|c|c|c|c|c|c|c|c|c|}
\hline Año & 1996 & 1997 & 1998 & 1999 & 2000 & 2001 & 2002 & 2003 & 2004 & 2005 & 2006 & 2007 & Total \\
\hline Número & 6 & 6 & 7 & 11 & 32 & 22 & 17 & 5 & 10 & 7 & 18 & 3 & 144 \\
\hline
\end{tabular}

FUENTE: elaboración propia con datos tomados de los expedientes analizados.

De los 144 casos, los partidos políticos nacionales han promovido en 136 ocasiones y los partidos políticos estatales sólo en ocho. Los partidos políticos nacionales, a través de sus dirigencias nacionales, han recurrido en 125 ocasiones normas electorales locales. Ello explicaría que la actividad de las dirigencias estatales en esta materia es mínima (cinco casos). Dicho comportamiento podría explicarse por la concentración de las competencias técnicas y financieras para interponer el litigio constitucional a nivel central.

\section{Acciones acumuladas}

Existen 35 acciones acumuladas que representan 101 casos individuales. Visto así, dicha cantidad representa poco más de la tercera parte de las acciones interpuestas. Esto se muestra en la siguiente tabla:

20 Esto no implica que las normas generales de esas entidades hayan sido recurridas por otros promoventes y a través de otros instrumentos (controversias o amparos). 
Tabla 7. Acciones de inconstitucionalidad acumuladas

\begin{tabular}{|l|c|}
\hline \multicolumn{1}{|c|}{ Promoventes } & $\begin{array}{c}\text { Número de acciones } \\
\text { acumuladas }\end{array}$ \\
\hline Partidos & 24 \\
\hline Partido-legislatura estatal & 5 \\
\hline Partido-Procurador & 1 \\
\hline Partido-APN & 1 \\
\hline Procurador-Diputados & 3 \\
\hline Procurador-legislatura estatal & 1 \\
\hline Total & 35 \\
\hline
\end{tabular}

FUENTE: elaboración propia con datos tomados de los expedientes analizados.

Como puede observarse, la acumulación se genera principalmente en materia electoral, pues los partidos políticos únicamente pueden recurrir dicha materia.

\section{Materia}

Para identificar la materia de las controversias se incluyó en la base de datos un campo que permitiera clasificarla de acuerdo con los siguientes rubros: administrativa, civil, electoral, fiscal, mercantil, orgánica y penal. ${ }^{21}$ Con base en esta clasificación se generó un indicador que relaciona cuantitativamente número de acciones y materia impugnada, con la finalidad de observar cuáles son las materias que se recurren con más frecuencia. Un segundo indicador permitió analizar la relación entre actores y materias, con el objeto de analizar si existe una correspondencia entre los actores y el tipo de leyes que impugnan. Por último, se examinó cuá-

21 Es importante señalar que en fechas recientes se han recurrido nuevas materias, tales como la que se refiere a la actividad económica nacional, reflejada en los siguientes ordenamientos: Ley de Desarrollo Sustentable de la Caña de Azúcar y Ley Federal de Competencia Económica, identificadas con los respectivos expedientes 27/2005 y 33/ 2006. Asimismo, en el ámbito estatal, ha tenido cabida la impugnación de los derechos de los gobernados en general, y específicamente de los niños y adolescentes, para lo cual se han controvertido, entre otras, la Ley de Cultura Cívica del Distrito Federal (expediente $21 / 2004$ ) y Ley de los Derechos de la Niñez y la Adolescencia del Estado de Campeche (expediente 24/2004). 
les son los artículos constitucionales más recurridos, con la finalidad de desprender si existen disposiciones constitucionales con base en las cuáles se interpongan con mayor frecuencia acciones de inconstitucionalidad.

El siguiente cuadro muestra la materia de las acciones de inconstitucionalidad:

Tabla 8. Número de acciones y porcentaje en relación con la materia

\begin{tabular}{|l|c|c|c|c|c|c|c|c|}
\hline Materias & Electoral & Fiscal & Administrativa & Penal & Orgánica $^{22}$ & Civil & Mercantil & Total \\
\hline Número & 169 & 90 & 23 & 7 & 6 & 5 & 1 & 301 \\
\hline Porcentaje & $56 \%$ & $29.9 \%$ & $8 \%$ & $2.3 \%$ & $1.9 \%$ & $1.6 \%$ & $0.3 \%$ & $100 \%$ \\
\hline
\end{tabular}

FUENTE: elaboración propia con datos tomados de los expedientes analizados.

Como puede observarse, las materias electoral y fiscal concentran la mayor parte de la acciones de inconstitucionalidad, aunque la diferencia porcentual entre una y otra es muy alta.

En cuanto a la materia fiscal, es interesante observar que el $95 \%$ de las acciones de inconstitucionalidad promovidas tienen como materia aspectos relacionados con egresos e ingresos, el 3\% se refiere a cuestiones relacionadas con catastro y sólo $2 \%$ con la coordinación fiscal.

Por lo que respecta a la materia administrativa, los temas más recurridos se relacionan con la rama municipal, la asistencia social, los servicios y la creación de órganos administrativos. Resulta interesante observar que casi el 50\% de las acciones en materia administrativa se refieren a la creación de órganos, institutos y organismos descentralizados a nivel estatal, y que el principal motivo de controversia tiene que ver con el régimen laboral de dichas instituciones.

En lo relativo a la materia electoral, normalmente las acciones interpuestas versan sobre dos o más temas, por lo que se decidió referirlos separadamente. Así, en 85 ocasiones se aludió a violaciones del procedimiento legislativo; 46 a financiamiento; 42 a representación proporcional; 36 a libertades y derechos; 37 a órganos electorales, integración y facultades;

22 Se distinguió la materia administrativa de la orgánica en razón del órgano regulado; así, los temas vinculados con los órganos de la administración pública recaen en la primera categoría; mientras que en la segunda se encuentran las impugnaciones de las leyes orgánicas de los poderes judiciales y legislativos. 
18 a distritación; 12 a partidos políticos, derechos, obligaciones y sanciones, así como vida interna; siete a mecanismos de participación ciudadana; 13 medios de impugnación a derechos político-electorales; tres a fiscalización y 31 a otros temas.

Lo anterior demuestra que los temas relacionados con el poder político y con el poder económico son los que más interesan a los órganos legitimados. En un segundo plano se encuentran los temas relacionados con libertades y derechos, integración y facultades de los órganos electorales y distritación. Esto significa que los partidos políticos se preocupan no sólo por las reformas jurídicas que inciden en su ámbito político o económico, sino que además siguen de cerca las reformas que versan sobre el órgano electoral que los regula y buscan impactar naturalmente tanto en su integración como en sus facultades. La siguiente tabla sintetiza estas conclusiones.

Tabla 9. Órganos legitimados y materias que se impugnan con mayor frecuencia

\begin{tabular}{|l|c|l|}
\hline \multicolumn{1}{|c|}{ Organismo } & Número de impugnaciones & \multicolumn{1}{|c|}{ Materia } \\
\hline Órganos legislativos federales & 5 & Fiscal: 3 \\
& & $\begin{array}{l}\text { Penal: 1 } \\
\text { Administrativa: 1 }\end{array}$ \\
\hline Procurador general de la República $^{23}$ & 95 & Fiscal: 74 \\
& & Administrativa: 12 \\
& & Electoral: 6 \\
Civil: 1 \\
\end{tabular}

23 Cabe mencionar que el actual procurador Eduardo Medina Mora Icaza ha interpuesto 42 acciones, de las cuales tres son en materia electoral y las demás en materia fiscal. Por su parte, el ex procurador Cabeza de Vaca, interpuso 30 acciones promovidas referentes a la materia fiscal, específicamente a egresos e ingresos. Por su parte el ex procurador Rafael Macedo de la Concha interpuso 23 acciones, de las cuales: nueve acciones en materia administrativa, 8 en materia fiscal, tres en materia electoral, 1 en materia civil, una en materia penal y una en materia mercantil. No obstante la principal diferencia, como se ha venido exponiendo, radica en el tiempo en que se interpusieron dichas acciones y el sentido en que se resolvieron. 


\begin{tabular}{|l|l|l|}
\hline Órganos legislativos estatales $^{24}$ & 56 & Electoral: 18 \\
& & Fiscal: 12 \\
Administrativa: 10 \\
Orgánica: 7 \\
Civil: 4 \\
Penal: 5 \\
\hline Partidos políticos $^{25}$ & & Violaciones durante el \\
procedimiento legislati- \\
vo:26 83 \\
Financiamiento: 46 \\
Representación propor- \\
cional: 42 \\
\end{tabular}

FUENTE: elaboración propia con datos tomados de los expedientes analizados.

Del cuadro anterior puede observarse que mientras las legislaturas locales impugnan con mayor frecuencia normas de carácter electoral y en menor medida en materia fiscal, ésta es la materia en la que el procurador general de la República actúa predominantemente.

La materia electoral es por mucho la más controvertida, particularmente, por los partidos políticos. Es de destacarse el elevado número de acciones interpuestas por violaciones durante el procedimiento legislativo, incluso se observa que de los 83 casos, en la tercera parte se recurrieron actos de aplicación, ${ }^{27}$ lo cual evidencia el desconocimiento por parte de los partidos de las cuestiones que no son objeto de control de la ac-

24 Si se analizan únicamente los datos correspondientes a la Asamblea Legislativa del Distrito Federal, que como se señaló es el órgano que mayor número de acciones ha interpuesto, se tiene que ha recurrido la materia electoral en tres ocasiones; dos en materia penal; una en civil; una administrativa y una fiscal.

25 Los partidos políticos sólo pueden impugnar leyes en materia electoral, razón por la cual, se analiza su participación desde el punto de vista del tema recurrido.

26 Tales como falta de fundamentación y motivación para expedir una norma, falta de oportunidad en la aprobación de la misma, omisiones legislativas, etcétera.

27 Véase anexo Tesis Jurisprudenciales bajo el rubro: ACCIÓN DE INCONSTITUCIONALIDAD. LAS PARTES LEGITIMADAS PARA PROMOVERLA SÓLO ESTÁN FACULTADAS PARA DENUNCIAR LA POSIBLE CONTRADICCIÓN ENTRE UNA NORMA GENERAL Y LA PROPIA CONSTITUCIÓN. 
ción de inconstitucionalidad. Una implicación de lo anterior es el uso de la acción constitucional por parte de los partidos políticos —o sus abogados- principalmente para controvertir cuestiones de forma, y menos para asuntos relacionados con la materia de la ley impugnada.

Ahora bien, resulta interesante observar cuáles son los artículos constitucionales más utilizados en las acciones de inconstitucionalidad. El análisis realizado muestra que son los siguientes: 16, 116, 41, 133 y 14 . A continuación los vincularemos con las materias para tener una visión más detallada.

\section{A. Materia electoral}

En esta materia los artículos más invocados son el 41 y el 116, lo cual resulta lógico si se toma en consideración que éstos contienen los principios y reglas relativas a los partidos políticos, organización de las elecciones e integración del órgano comicial federal, así como diversas normas que deben seguir las legislaturas locales en la configuración de su sistema electoral.

Por otro lado, se observa que a menudo se argumenta la vulneración de los artículos 14 y 16 constitucionales como una especie de muletilla en relación con otros artículos impugnados, o bien, para demandar aspectos formales del procedimiento, violaciones a los principios de legalidad, seguridad jurídica y el debido proceso. Es decir, los promoventes invocan la violación de dichos preceptos para "reforzar" sus planteamientos; no obstante, tal como se verá ulteriormente, en pocas ocasiones la Corte ha determinado que efectivamente existen transgresiones a estos artículos. Una situación similar se da con el artículo 133, en cuyo caso se argumenta lateralmente que se violenta el principio de supremacía constitucional.

\section{B. Materia administrativa}

En esta materia, el artículo más impugnado es el 123 en materia laboral. Ello se debe a que en las acciones en las que se argumentó la violación del artículo referido tuvieron como base la expedición de leyes por las que se crearon organismos descentralizados. El motivo específico de inconformidad fue el estatus de los trabajadores de dichos institutos. 


\section{Materia civil}

Si bien en esta materia no se presentan muchas impugnaciones, se observa que el artículo 1o. en relación con el artículo 13 constitucional son las disposiciones más frecuentemente invocadas. Esto se debe principalmente a que se han impugnado facultades excepcionales que las leyes de notariado otorgan a los Consejos de Notarios, pues se considera que éstas atentan contra el principio de igualdad y la prohibición de que una persona sea juzgada por leyes o tribunales especiales.

\section{Materia fiscal}

Los artículos más utilizados en esta materia son el 16 en relación con el 73. Los temas más frecuentemente recurridos tienen que ver con las facultades que corresponden a los poderes legislativos - Federal y estatales- para establecer contribuciones fiscales en diversos ámbitos, la litis versa en particular respecto de la invasión de la esfera federal por parte de los estados cuando regulan cuestiones impositivas.

En esta materia se observa también que con frecuencia la PGR argumenta que, como consecuencia de las violaciones constitucionales alegadas, se violenta el principio de supremacía constitucional previsto en el artículo 133 de la Constitución federal, toda vez que la norma general cuya invalidez se solicita, se encuentra en un nivel jerárquico inferior a la Constitución.

\section{E. Materia penal}

La materia penal registró una mayor impugnación sobre el artículo 21 constitucional, en relación con dos temas: por un lado la reforma a la Constitución que facultó al Congreso de la Unión para que expidiera una ley que fijara las bases para la coordinación entre los tres niveles de gobierno, en el marco de un sistema nacional de seguridad pública; por el otro, se recurrieron asuntos relacionados con la imposición de las penas y las facultades del Ministerio Público en la investigación y persecución de los delitos. 


\section{Sentido de las resoluciones}

Resulta importante conocer el resultado de las acciones interpuestas por los sujetos legitimados, es decir, en qué número de ellas la Suprema Corte ha estimado que efectivamente se contraviene un precepto constitucional. Para tal efecto se utilizaron diferentes indicadores que exponemos a continuación.

\section{A. Procedencia}

En primer término se realizó un análisis para determinar el número de acciones procedentes, improcedentes y aquellas que se desestimaron. Ello permite observar el porcentaje de casos en que la Corte entró al fondo del asunto. El cuadro siguiente resume los resultados:

Tabla 10. Acciones procedentes, improcedentes y desestimadas.

\begin{tabular}{|c|c|c|c|c|}
\hline Sentido & Procedentes & $\begin{array}{c}\text { Improcedentes } \\
\text { (sobreseida o desechada) }\end{array}$ & Desestimadas & Total \\
\hline Número & 243 & 50 & 22 & $315^{28}$ \\
\hline
\end{tabular}

FUENTE: elaboración propia con datos tomados de los expedientes analizados.

Como puede observarse, en $77 \%$ de casos la Corte estudió los conceptos de invalidez planteados por las partes, es decir, conoció el fondo del asunto. Si se consideran únicamente este universo, es decir, las acciones procedentes $(\mathrm{n}=243)$, el resultado es el siguiente:

28 Si bien el número de acciones estudiadas es 301, existen 14 casos en que se presentaron votaciones diferenciadas. Se trata de los expedientes: 10/2000, 13/2002 y 19/ 2004 (se desestima en una parte y es infundada en otra); 11, 15 y 16/2004, 30/2005, $26 / 2006,28 / 2006,45 / 2006,149 / 2007$ y $150 / 2007$ (se desestima en una parte y es parcialmente fundada en otra) $22 / 2004$ (se sobresee en una parte y se desestima en otra) y 28/2005 (se desestima en una parte y es fundada en otra). En tales casos, debido a que se toma en cuenta el número de acciones desestimadas, así como el número de las acciones parcialmente fundadas e infundadas, se presentan 315 supuestos. 
Tabla 11. Sentido de la resolución de la SCJ sobre las acciones procedentes

\begin{tabular}{|l|c|c|c|c|}
\hline Sentido & Fundadas & $\begin{array}{c}\text { Parcialmente } \\
\text { fundadas }\end{array}$ & Infundadas & Total \\
\hline Número & 91 & 79 & 73 & 243 \\
\hline
\end{tabular}

FUENTE: elaboración propia con datos tomados de los expedientes analizados.

De estos datos se desprende que prácticamente en el $70 \%$ de los casos en los que la Suprema Corte de Justicia ha entrado al fondo, ha estimado que existe, total o parcialmente, una violación a la Constitución. Visto de otro manera, y tomando el total de las acciones de la muestra ( $\mathrm{n}=315$ incluyendo improcedencia y desestimadas), en el 54\% de los casos se ha encontrado que existe una violación a la Constitución. En otras palabras, una de cada dos acciones que se promueven resulta fundada o parcialmente fundada.

Un análisis más detallado de los resultados considerando ahora el órgano legitimado que las promovió arroja los siguientes datos:

Tabla 12. Órganos legitimados, número de acciones presentadas y sentido

\begin{tabular}{|c|c|c|c|}
\hline & $\begin{array}{l}\text { Número de } \\
\text { acciones } \\
\text { presentadas }\end{array}$ & Sentido 2 & \\
\hline \multirow[t]{4}{*}{ Órganos legislativos federales } & \multirow[t]{4}{*}{5} & Fundadas & 2 \\
\hline & & Parcialmente fundadas & 1 \\
\hline & & Infundadas & 1 \\
\hline & & Sobresee/Desecha & 1 \\
\hline \multirow[t]{3}{*}{ Procurador general de la República } & \multirow[t]{3}{*}{95} & Fundadas & 66 \\
\hline & & Parcialmente fundadas & 8 \\
\hline & & Infundadas & 7 \\
\hline
\end{tabular}

29 El número de acciones presentadas por los órganos legitimados suman 300, no 301, debido a que se presentó un caso en que la acción de inconstitucionalidad fue promovida por una agrupación política nacional, órgano no legitimado en este medio de control constitucional. 


\begin{tabular}{|c|c|c|c|}
\hline & & Sobresee/desecha & 7 \\
\hline & & Desestima & 7 \\
\hline \multirow[t]{5}{*}{ Órganos legislativos estatales } & \multirow[t]{5}{*}{56} & Fundadas & 8 \\
\hline & & Parcialmente fundadas & 17 \\
\hline & & Infundadas & 16 \\
\hline & & Sobresee/desecha & 11 \\
\hline & & Desestima & 4 \\
\hline \multirow[t]{5}{*}{ Partidos políticos } & \multirow[t]{5}{*}{144} & Fundadas & 15 \\
\hline & & Parcialmente fundadas & 51 \\
\hline & & Infundadas & 46 \\
\hline & & Sobresee/desecha & 30 \\
\hline & & Desestima & 2 \\
\hline
\end{tabular}

FUENTE: elaboración propia con datos tomados de los expedientes analizados.

Existen varios aspectos interesantes que se desprenden del cuadro anterior. Con excepción del procurador general de la República ninguno de los órganos legitimados ha logrado que más del 50\% de las acciones que ha promovido sean fundadas o parcialmente fundadas. En el caso del procurador, en el $69 \%$ de los casos se ha declarado la invalidez de la norma impugnada, no obstante, si se eliminan los datos de 2006 y 2007, la estadística es casi un 30\% menos consistente. Ello puede explicarse, como ya se sugirió, por la especialización técnica del promovente. Ello contrasta con el desempeño de los partidos políticos que obtienen los peores resultados. Sólo 15 de 144 acciones resultaron fundadas y 51 parcialmente fundadas.

En cuanto a las legislaturas de los estados, el análisis detallado genera los siguientes resultados: 
Tabla 13. Acciones presentadas por las legislaturas de las entidades y sentido

\begin{tabular}{|l|l|}
\hline \multicolumn{1}{|c|}{ Sentido } & \multicolumn{1}{c|}{ Legislaturas } \\
\hline Fundadas & $\begin{array}{l}\text { Sonora (2), Veracruz (2), Baja California Sur (1), Baja Cali- } \\
\text { fornia (1), Campeche (1) y Chiapas (1). }\end{array}$ \\
\hline Parcialmente fundadas & $\begin{array}{l}\text { Aguascalientes (2), Colima (2), Chihuahua (2), D F (2), Mo- } \\
\text { relos (2), Nuevo León (2), Yucatán (2), Baja California Sur } \\
\text { (1), Jalisco (1) y Tabasco (1). }\end{array}$ \\
\hline Infundadas & $\begin{array}{l}\text { Aguascalientes (3), Nuevo León (3), Yucatán (2), } \\
\text { Chihuahua (1), Coahuila (1), Durango (1), Hidalgo (1), Mé- } \\
\text { xico (1), Querétaro (1), Sinaloa (1) y D F (1). }\end{array}$ \\
\hline Sobresee y se desecha & $\begin{array}{l}\text { DF (3), Sinaloa (2), Chihuahua (1), Durango (1), Michoacán } \\
\text { (1), San Luis Potosí (1), Sonora (1) y Tabasco (1). }\end{array}$ \\
\hline Desestima & D F (2), Yucatán (1) y Chihuahua (1). \\
\hline Total & \multicolumn{1}{c}{56} \\
\hline
\end{tabular}

FUENTE: Elaboración propia con datos tomados de los expedientes analizados.

En este caso no encontramos una correlación significativa de los resultados. Así, Aguascalientes presenta dos acciones parcialmente fundadas y tres infundadas, mientras que Nuevo León y Yucatán presentan dos parcialmente fundadas y tres y dos infundadas respectivamente, en contraste con legislaturas como las de Campeche y Chiapas, que promovieron en una sola ocasión y ésta fue fundada. El caso de la Asamblea Legislativa del Distrito Federal de las ocho acciones interpuestas, tres se sobreseen, dos se desestiman, una es infundada y sólo dos son parcialmente fundadas.

\section{B. Disposiciones efectivamente violadas}

El siguiente cuadro presenta los artículos impugnados en más de 20 ocasiones relacionados con el número de veces en que la Corte concluyó que efectivamente habían sido vulnerados. ${ }^{30}$

30 Para ver la tabla completa consúltense los anexos en http://www.cide.edu/investi gador/sitios.php?IdInvestigador $=1079$. 
Tabla 14. Relación entre los artículos constitucionales impugnados y efectivamente vulnerados

\begin{tabular}{|c|c|c|c|}
\hline $\begin{array}{c}\text { Articulos } \\
\text { constitucionales }\end{array}$ & $\begin{array}{c}\text { Número de } \\
\text { veces impugnado }\end{array}$ & $\begin{array}{c}\text { Número de veces } \\
\text { efectivamente violentado }\end{array}$ & $\begin{array}{c}\text { Porcentaje } \\
\text { de artículos violentados }\end{array}$ \\
\hline 10. & 58 & 4 & $6.9 \%$ \\
\hline 60. & 22 & 1 & $4.5 \%$ \\
\hline 90. & 37 & 0 & $0.0 \%$ \\
\hline 14 & 136 & 19 & $14.0 \%$ \\
\hline 16 & 211 & 64 & $30.3 \%$ \\
\hline 17 & 41 & 6 & $14.6 \%$ \\
\hline 22 & 51 & 43 & $84.3 \%$ \\
\hline 35 & 44 & 7 & $15.9 \%$ \\
\hline 40 & 73 & 8 & $11.0 \%$ \\
\hline 41 & 159 & 33 & $20.8 \%$ \\
\hline 54 & 28 & 14 & $50.0 \%$ \\
\hline 72 & 23 & 2 & $8.7 \%$ \\
\hline 73 & 54 & 39 & $72.2 \%$ \\
\hline 105 & 63 & 11 & $17.5 \%$ \\
\hline 115 & 47 & 7 & $14.9 \%$ \\
\hline 116 & 161 & 77 & $47.8 \%$ \\
\hline 124 & 66 & 1 & $1.5 \%$ \\
\hline 133 & 147 & 22 & $15 \%$ \\
\hline
\end{tabular}

FUENTE: elaboración propia con datos tomados de los expedientes analizados.

Existen varios aspectos que sobresalen de la tabla anterior. El primero, es que no existe una relación entre los artículos que los promoventes consideran violados con más frecuencia con aquellos que la Corte determina que en efecto existió una violación. Por ejemplo, los artículos $14 \mathrm{y}$ 16 , relacionados con las garantías de legalidad y seguridad jurídica, fueron considerados como violentados en 136 y 211 ocasiones, pero se determinó que fueron efectivamente transgredidos sólo en 19 y 64 ocasiones, es decir, 14 y 30\%, respectivamente.

Los artículos 41 y 116 tienen también un alto porcentaje de impugnación (159 y 161 veces, respectivamente), relativos a la materia electoral y las facultades de las entidades federativas. Dado el alto porcentaje de ac- 
ciones que se refieren a estas materias, no resulta sorprendente tal situación. El porcentaje de veces que se han declarado violentados es relativamente bajo para el artículo 41 (21\%) y más significativo para el $116(50 \%)$.

Por último, en cuanto al artículo 133, suele invocarse con un propósito similar al de los artículos 14 y 16, sólo que, a diferencia de éstos, y teniendo como base la vulneración del principio de supremacía constitucional, de resultar fundado cualquier concepto de invalidez, como consecuencia lógica, se consideraba vulnerado el artículo 133. No obstante lo anterior, es de destacarse que a pesar de que se invocó en 147 ocasiones, sólo se declaró efectivamente violado 15 veces $(22 \%)$.

\section{Acciones sobreseidas, desechadas y desestimadas}

Las razones para sobreseer, desechar o desestimar acciones se distribuyen de la siguiente manera:

Tabla 15. Relación entre las acciones y causales de sobreseimiento o desechamiento

\begin{tabular}{|l|c|}
\hline \multicolumn{1}{|c|}{ Causales } & $\begin{array}{c}\text { Número } \\
\text { de acciones }\end{array}$ \\
\hline Presentación extemporánea & 15 \\
\hline Cesaron los efectos de la norma & 12 \\
\hline Falta de legitimación & 9 \\
\hline Materia de otra ejecutoria & 5 \\
\hline No se impugnan normas generales & 3 \\
\hline Conductas de omisión & 2 \\
\hline $\begin{array}{l}\text { Otros (sin conceptos de invalidez, no existe la } \\
\text { norma, etcétera) }\end{array}$ & 4 \\
\hline Total & 50 \\
\hline
\end{tabular}

FUENTE: elaboración propia con datos tomados de los expedientes analizados.

Como puede observarse, la causal que con mayor frecuencia se presenta se refiere a la extemporaneidad. Esto lleva a preguntarse si el plazo establecido para la promoción es idóneo o si conviene ampliarlo para extender la posibilidad que los órganos legitimados interpongan una acción de inconstitucionalidad. 
Una segunda reflexión es que con excepción de un caso, todas las acciones sobreseídas por esta causal corresponden a la materia electoral, la cual tiene un régimen distinto en su tramitación, se trata de plazos más cortos para la sustanciación y resolución del procedimiento, con la finalidad de tener certeza respecto de las leyes aplicables al proceso electoral del que se trate.

En los casos desechados por omisiones legislativas de los congresos estatales, la Corte ha considerado que esos actos no pueden ser considerados como normas generales, pues carecen de los elementos necesarios como son la promulgación y publicación, y por tanto, no producen efectos legales. ${ }^{31}$ No obstante, la Corte determinó recientemente que tal criterio no es aplicable cuando se trate de una omisión parcial resultado de una deficiente regulación de las normas respectivas. ${ }^{32}$

Por otro lado, la Corte determinó sobreseer en dos ocasiones los decretos de presupuestos de las entidades, por considerar que no se trataba de normas generales. ${ }^{33}$ En este tema, otra acción desechada derivó de un decreto expedido por el legislativo, y se determinó que éste no constituía una norma general susceptibles de impugnarse.

En cuanto a la cesación de efectos de la norma, la mayoría se debió a la impugnación de normas fiscales presupuestales, es decir, se trataba de normas con una vigencia anual que, cuando se pretendían resolver, ya se habían modificado o habían dejado de tener vigencia.

Referente a las acciones desestimadas, en su mayoría se trató de aquellas en que se sometía a debate si las relaciones laborales que se dan entre los organismos descentralizados creados por las legislaturas de los estados y por la Asamblea Legislativa del Distrito Federal y sus respecti-

31 ACCIÓN DE INCONSTITUCIONALIDAD. ES IMPROCEDENTE EN CONTRA DE LA OMISIÓN DE APROBAR LA INICIATIVA DE REFORMAS A UNA CONSTITUCIÓN LOCAL. Jurisprudencia P./J. 23/2005.

32 ACCIÓN DE INCONSTITUCIONALIDAD. SI BIEN ES IMPROCEDENTE CONTRA UNA OMISIÓN ABSOLUTA EN LA EXPEDICIÓN DE UNA LEY, NO LO ES CUANDO AQUÉLLA SEA RESULTADO DE UNA DEFICIENTE REGULACIÓN DE LAS NORMAS RESPECTIVAS. Jurisprudencia P./J. 5/2008.

33 Al respecto, véase la tesis: ACCIÓN DE INCONSTITUCIONALIDAD. ES IMPROCEDENTE PARA REClAMAR El DECRETO DEL PRESUPUESTO DE EGRESOS DEL Distrito FEDERAL PARA EL EJERCICIO FISCAL DE 1998, POR NO TENER EL CARÁCTER DE NORMA GENERAL. Jurisprudencia P./J. 24/99. 
vos trabajadores deben regirse por el apartado B del artículo 123 de la Constitución federal.

\section{Votación}

En esta sección se analizan las acciones de inconstitucionalidad en relación con su votación, es decir, con qué frecuencia existe un acuerdo unánime en la resolución de los asuntos, y en qué medida la votación se dispersa, constituyendo mayoría, o bien, empates. Para tal efecto, se construyeron los siguientes indicadores:

El primero de ellos se refiere a la unanimidad en la votación independientemente del sentido de las resoluciones, con el objetivo de observar el grado de consenso que existe en la Suprema Corte de Justicia de la Nación al resolver las acciones; el segundo se refiere a la votación divergente, y se analizan brevemente los casos en que se emitieron mayor cantidad de votos particulares de los ministros (ya sea que se trate de votos concurrentes, minoritarios, conjuntos, de mayoría, de mayoría no calificada o aclaratorios). ${ }^{34}$

Vale la pena recordar que las declaraciones de inconstitucionalidad que emite la Suprema Corte como resultado de una acción requieren una votación de cuando menos ocho votos. Ismael Reyes Retana ${ }^{35}$ señala que en la iniciativa presidencial para reformar el artículo 105 constitucional se proponía que la mayoría se constituyera por nueve ministros; sin embargo, en el dictamen elaborado por la cámara de origen se señaló que con objeto de hacer viables las declaraciones de inconstitucionalidad con efectos generales era necesario reducir de nueve a ocho el quórum de votación. ${ }^{36}$ Esta votación calificada ha generado un debate importante entre quienes sostienen que no tiene sentido y quienes consideran que, por el

34 El supuesto del que se parte para analizar los expedientes con mayor número de votos particulares es que en esos casos los ministros discreparon sustantivamente durante la discusión del asunto; prueba de ello es que en todos estos casos las acciones de inconstitucionalidad fueron desestimadas.

35 Reyes Retana, Ismael, "Apuntes sobre los efectos de las resoluciones en controversias constitucionales y acciones de inconstitucionalidad", Jurípolis, Revista de Ciencia Política y Derecho del ITESM, CCM, año 3, vol. 1, 2003.

36 Dictamen de la reforma constitucional elaborado por la Cámara de Senadores. 
contrario, existen razones para mantenerlo. ${ }^{37}$ Analizaremos esta cuestión a la luz de la evidencia empírica.

\section{A. Votación unánime}

Previo al análisis de la evidencia empírica es pertinente aclarar que para efectos del presente apartado se considera que la votación es unánime cuando todos los ministros en una sesión votaron en el mismo sentido, con independencia del número de presentes. Esto atiende al hecho de que de las 315 ocasiones en que se votaron las acciones de inconstitucionalidad sujetas a análisis, únicamente en el $40 \%$ de los casos concurrieron a la sesión los 11 ministros. En muchas ocasiones el número de ministros fue menor a 11, pero todos votaron en el mismo sentido, casos en que consideramos existió unanimidad.

Así, la siguiente tabla muestra el número de casos en que, conforme al criterio antes mencionado, la votación fue unánime:

Tabla 16. Votación unánime

\begin{tabular}{|l|c|c|c|c|c|c|c|}
\hline Votos & 11 & 10 & 9 & 8 & 5 & 4 & Total \\
\hline Número de acciones & 126 & 86 & 26 & 15 & 3 & 4 & 260 \\
\hline
\end{tabular}

FUENTE: elaboración propia con datos tomados de los expedientes analizados.

Una de las primeras cuestiones que se pueden destacar de lo anterior es que se observa que existen casos en los cuales la votación, si bien fue por unanimidad, se determinó por cinco y cuatro votos; ello obedece a la resolución de algunos expedientes por parte de las salas de la Corte, en atención al Acuerdo del Pleno 5/2001.38

Los datos muestran que en 260 ocasiones de un total de 315 se votó de manera unánime por el cuerpo colegiado, en otras palabras que en el $82 \%$ de los casos existió consenso entre los ministros.

37 Véase Caballero, José Antonio et al., op cit., nota 1, pp. 153 y 154.

38 El acuerdo del Pleno 5/2001 delegó a las Salas de la Corte aquellos asuntos en que fuera innecesaria la intervención del Pleno. La interpretación que se realizó en la práctica de la Suprema Corte de Justicia de la Nación es que será innecesaria su intervención en aquellos asuntos en que no se vaya a estudiar y resolver el fondo del asunto. 


\section{B. Votación divergente}

Así, los datos indican un alto porcentaje de unanimidad; sin embargo, un análisis cualitativo muestra que ésta es más frágil cuando se analizan temas más controvertidos o complejos.

Así, por ejemplo, en la materia electoral, en los expedientes 14/2004 y sus acumulados; 28/2005 así como 28/2006 y sus acumulados, se discutió la distritación (la causa de la diferencia de criterios radicó en desentrañar si ésta debía seguir un criterio geográfico o poblacional); la integración de órganos (relacionada con la designación de candidatos a gobernador, ya que en los casos de falta o ausencia del gobernador electo, la selección del gobernador interino se haría a través de una terna formulada por la fracción parlamentaria del partido político al que perteneció el gobernador que se sustituye); candidaturas independientes (por lo que respecta al financiamiento que el candidato independiente triunfador podrá obtener con motivo de los gastos de campaña que haya erogado). ${ }^{39}$

En materia penal, es interesante el asunto 10/2000 en que se recurrieron las reformas al Código Penal para el Distrito Federal, por considerarlo contrario a las garantías individuales contenidas en los artículos 1o., 14, 17 y 22 de la Constitución general de la República, que preveían la exclusión de la sanción por el delito de aborto en el supuesto de que el producto presente alteraciones genéticas, a juicio de dos médicos especialistas. ${ }^{40}$

Por lo que respecta a la materia mercantil, en el expediente 12/2002 el procurador general de la República alegó la incompetencia de la Asamblea Legislativa para expedir las normas que regulen aspectos relativos a las medidas de seguridad de las instituciones de banca múltiple, pues según su opinión corresponde al Congreso de la Unión legislar en materia de intermediación y servicios financieros, la cual incluiría el aspecto de

39 En el caso del expediente 14/2004 y sus acumulados por unanimidad de 10 votos se declaró parcialmente fundada la acción, y en otra parte se desestimó (se emitieron siete votos particulares). En el expediente 28/2005; por siete votos a favor y tres en contra se declaró fundada la acción y en otra se desestimó (se emitieron cuatro votos particulares). Por lo que respecta al expediente $28 / 2006$, por ocho votos a favor y tres en contra se declaró parcialmente fundada la acción y en otra se desestimó (se emitieron dos votos particulares).

40 En este expediente, la acción se declaró infundada por siete votos contra cuatro, y otra parte se desestimó. Asimismo, se emitieron siete votos particulares. 
su seguridad y protección. Este caso no deja de ser relevante, pues además se trata del único supuesto alegado en materia mercantil. ${ }^{41}$

Por último, en materia administrativa la acción de inconstitucionalidad 26/2006 $6^{42}$ presenta votaciones diferenciadas en múltiples temas, tales como: la improcedencia de la acción de inconstitucionalidad respecto de la omisión legislativa denunciada; la creación de la Comisión Federal de Telecomunicaciones como órgano desconcentrado; los requisitos que deben cumplir los permisionarios para operar una estación de radiodifusión; duración del cargo de los comisionados, así como inelegibilidad de los integrantes de la anterior Comisión Federal de Telecomunicaciones para integrarla nuevamente; la facultad de objeción del Senado a los nombramientos de los integrantes de la Comisión Federal de Telecomunicaciones, etcétera.

En síntesis, algunos de los temas más polémicos que han sido materia de acciones de inconstitucionalidad son también aquéllos en los que se ha presentado la votación y argumentación más variada entre los ministros. Llama también la atención que dichos casos tratan asuntos distintos a aquellos que los sujetos legitimados impugnan con mayor frecuencia, tales como el aborto, las telecomunicaciones o las candidaturas independientes. En realidad, en la medida en que se controvierten materias distintas a las habituales y se plantean argumentos jurídicos novedosos ante la Suprema Corte de Justicia de la Nación, los ministros se ven obligados a formular nuevos criterios normativos, mismos que generan debate y permiten observar un papel más activo de la Corte en la definición de los temas fundamentales para el país.

\section{Tiempos de resolución}

Este apartado tiene por objeto analizar el tiempo promedio en que resuelve la Corte las acciones de inconstitucionalidad. ${ }^{43}$

41 Por diez votos contra uno, se desechó la acción, se desestimó en otra parte. Asimismo, se emitieron tres votos particulares.

42 Por unanimidad de nueve votos, se declaró parcialmente fundada la acción, y en otra parte se desestimó. Se emitieron nueve votos particulares.

43 Con el propósito de realizar el conteo de los tiempos previstos para la materia electoral se consideró que el artículo segundo transitorio del Decreto mediante el cual se declaran reformados diversos artículos de la Constitución Política de los Estados Unidos Mexicanos, publicado en el Diario Oficial de la Federación del 22 de noviembre de 
El tiempo promedio en que la Suprema Corte ha resuelto las acciones de inconstitucionalidad es de siete meses, dos semanas, dos días. ${ }^{44}$ Desglosado por materias el resultado es el siguiente:

Tabla 17. Tiempo promedio en que resuelve la corte en relación con las materias

\begin{tabular}{|l|l|}
\hline Materias & Promedio \\
\hline Civil & un año, dos meses, siete días \\
\hline Penal & un año, 20 días \\
\hline Administrativa & nueve meses, dos semanas, seis días \\
\hline Orgánica & nueve meses, tres días \\
\hline Fiscal & cuatro meses, dos semanas, \\
\hline Electoral & 62 días \\
\hline Mercantil* & dos meses, cuatro semanas, dos días \\
\hline
\end{tabular}

FUENTE: elaboración propia con datos tomados de los expedientes analizados.

* Existe sólo un caso, por lo que no se trata del promedio, sino de la resolución específica.

De los plazos anteriores, se pueden desprender dos consideraciones. La primera es que la materia electoral presenta el menor tiempo de reso-

1996, en relación con las reformas y adiciones a diversos preceptos de la Ley Reglamentaria de las Fracciones I y II del Artículo 105 de la Constitución General de la República, publicado en la fecha anteriormente reseñada, establece que el plazo para ejercitar las acciones de inconstitucionalidad en contra de las legislaciones electorales federal y locales, que se expidieron antes del 1o. de abril de 1997, es de 15 días naturales y deben ser resueltas de plano y en definitiva por la Suprema Corte de Justicia de la Nación en un plazo no mayor de 15 días hábiles a partir de la presentación del escrito respectivo. Así, únicamente en tales supuestos el conteo se realizó por días hábiles, en los demás casos, se trató de días naturales. En las demás materias, se eliminaron en el conteo los sábados, domingos y días no laborables para el Poder Judicial, de conformidad con los preceptos aplicables de la Ley Orgánica del Poder Judicial de la Federación. Posteriormente, se tomó como un mes la suma de 31 días, toda vez que existen más meses con este número de días en un año. De esta forma, el promedio al que se llegara se trataría del tiempo efectivo en que se resolvió.

$44 \mathrm{Al}$ sacar los promedios, se toman tan sólo los números enteros, por lo cual, si el resultado era de 0.5 hacia arriba, se establecía el número inmediato superior, si el resultado era 0.4 hacia abajo, se determinó el número inmediato inferior. 
lución, no obstante si bien la propia ley determina un plazo más breve para la sustanciación del procedimiento, no hay una disposición que refiera el tiempo total en que debe resolverse. El dato anterior es relevante si lo correlacionamos con la falta de calidad e innovación argumentativa que presentan los órganos legitimados. En efecto, en materia electoral se suelen observar que los promoventes usan los mismos agravios a través del tiempo, por lo que en su mayoría se trata de argumentos suficientemente estudiados por la Corte, situación que hipotéticamente reduce los tiempos de resolución.

Asimismo, la Suprema Corte ha emitido criterios que flexibilizan los tiempos de resolución; en tal sentido, ha interpretado que los plazos breves previstos para la materia electoral tienen que observarse en aquellos asuntos que deban resolverse dentro de los 90 días anteriores al inicio del proceso electoral en que vayan a aplicarse las normas impugnadas. ${ }^{45}$

En cuanto a la materia fiscal, se observa un tiempo relativamente largo para la resolución de las acciones de inconstitucionalidad, dato que resulta relevante si se considera que en su mayoría se impugnan leyes de ingresos y presupuestos de egresos estatales, leyes de ingresos municipales $\mathrm{y}$ algunas otras, instrumentos que suelen tener una vigencia anual. No debe olvidarse que la anualidad de dichas leyes tiene como finalidad fijar las contribuciones y otros ingresos que deban formar parte de los recursos públicos, por lo que la oportunidad de las resoluciones debe constituirse en un elemento importante. ${ }^{46} \mathrm{La}$ Corte ha realizado ciertamente un esfuerzo en esta materia, al reducir el periodo en que resuelve este tipo de asuntos, ya que a partir del expediente $21 / 2005$, el tiempo promedio ha oscilado entre los dos y dos meses y medio. Aun así, es pertinente reflexionar sobre la pertinencia de reducir aún más los tiempos de resolución pues tratándose de acciones de inconstitucionalidad no existe la po-

45 Véase el anexo Tesis jurisprudenciales bajo el rubro: ACCIÓN DE INCONSTITUCIONALIDAD EN MATERIA ELECTORAL. LOS PLAZOS BREVES PREVISTOS PARA LA SUSTANCIACIÓN DEL PROCEDIMIENTO RIGEN EN AQUELLOS ASUNTOS QUE DEBAN RESOLVERSE DENTRO DE LOS NOVENTA DÍAS ANTERIORES AL INICIO DEL PROCESO ELECTORAL EN QUE VAYAN A APLICARSE LAS NORMAS IMPUGNADAS.

46 En este punto, vale la pena revisar el expediente 4/2002, con motivo de la impugnación de la Ley de Ingresos y Presupuesto de Egresos de Sinaloa para el Ejercicio Fiscal del año 2002. En dicho caso, se decretó el sobreseimiento de la acción bajo el argumento de que ya habían cesado los efectos de la norma impugnada. Cabe agregar que la demanda se presentó el 18 de enero de 2002 y fue resuelta el 11 de marzo de 2003. 
sibilidad de dictar una suspensión, y por ello la norma impugnada sigue surtiendo sus efectos aunque se encuentre sub iudice. La siguiente tabla sintetiza los tiempo promedio de resolución por materia y órgano legitimado.

Tabla 18. Tiempos de resolución

\begin{tabular}{|c|c|c|c|}
\hline & Tiempo promedio en & \multicolumn{2}{|c|}{ Desglose por materias } \\
\hline \multirow[t]{3}{*}{$\begin{array}{l}\text { Órganos legislativos } \\
\text { federales }\end{array}$} & \multirow[t]{3}{*}{$\begin{array}{l}\text { cuatro meses, dos se- } \\
\text { manas, tres días }\end{array}$} & Fiscal & $\begin{array}{l}\text { seis meses, dos semanas, } \\
\text { cinco días }\end{array}$ \\
\hline & & Penal* & 1 mes, 1 semana, 1 día \\
\hline & & Administrativa* & $\begin{array}{l}\text { nueve meses, dos sema- } \\
\text { nas, seis días }\end{array}$ \\
\hline \multirow{4}{*}{$\begin{array}{l}\text { Procurador General } \\
\text { de la República }\end{array}$} & \multirow{4}{*}{$\begin{array}{l}\text { tres meses, dos sema- } \\
\text { nas, tres días }\end{array}$} & Fiscal & tres meses, tres días \\
\hline & & Administrativa & seis meses, seis días \\
\hline & & Electoral & 73 días \\
\hline & & Mercantil* & $\begin{array}{l}\text { dos meses, cuatro sema- } \\
\text { nas, dos días }\end{array}$ \\
\hline \multirow{6}{*}{$\begin{array}{l}\text { Órganos legislativos } \\
\text { estatales }\end{array}$} & \multirow{6}{*}{$\begin{array}{l}\text { ocho meses, dos sema- } \\
\text { nas, cinco días }\end{array}$} & Administrativa & un año, seis días \\
\hline & & Civil & $\begin{array}{l}\text { un año, un mes, dos se- } \\
\text { manas }\end{array}$ \\
\hline & & Electoral & 83 días \\
\hline & & Fiscal & $\begin{array}{l}\text { siete meses, una semana, } \\
\text { dos días }\end{array}$ \\
\hline & & Orgánica & $\begin{array}{l}\text { cinco meses, una sema- } \\
\text { na, un día }\end{array}$ \\
\hline & & Penal & $\begin{array}{l}\text { un año, un mes, dos se- } \\
\text { manas, tres días }\end{array}$ \\
\hline Partidos políticos & 59 días & & \\
\hline
\end{tabular}

FUENTE: elaboración propia con datos tomados de los expedientes analizados.

* Existe sólo un caso, por lo que no se trata de un promedio. 


\section{CONCLUSIONES}

En este artículo hemos presentado algunos datos que resultan de la sistematización de la información sobre acciones de inconstitucionalidad a partir de una base de datos relativamente artesanal. Las conclusiones deben ser tomadas con precaución pues, como en todo primer ejercicio, mucho hemos aprendido en el camino que nos obligaría a replantear algunos de los supuestos de partida. Por otro lado, y como consecuencia de la política de transparencia de la Suprema Corte de Justicia, la información disponible actualmente es mucho más amplia que la que existía cuando iniciamos este trabajo, lo cual abre nuevas vías para ejercicios más completos. Uno de los aspectos metodológicos más complejos es el relativo a cómo sistematizar la información que se desprende de las decisiones y los expedientes judiciales, en otras palabras, qué variables deben ser consideradas y cómo deben codificarse en una base de datos. Existen numerosos problemas en cuanto, por ejemplo la manera de determinar las votaciones (un asunto puede tener más de una votación) o a cómo sistematizar la materia. Todas estas cuestiones ameritarían una discusión importante. Nuestra base de datos y sus variables está disponible en Internet ${ }^{47}$ y pueden servir de base para una discusión más amplia sobre este asunto, que debe llevarnos a producir más y mejor información para el análisis.

No obstante lo anterior, los datos que presentamos en su conjunto son suficientemente robustos para extraer algunas conclusiones sugerentes. Un primer aspecto tiene que ver con la función misma de la acción de inconstitucionalidad como un mecanismo de control constitucional y la capacidad de las instituciones de darle un contenido efectivo. Desde esta perspectiva podemos concluir que, pese a diversas limitaciones, las acciones de inconstitucionalidad se han convertido en un procedimiento eficaz para el control constitucional. En efecto, si tomamos como referencia el conjunto de la muestra, podemos afirmar que en poco más del $50 \%$ de los casos la Suprema Corte de Justicia ha declarado fundadas o parcialmente fundadas las acciones interpuestas por los promoventes. Ello indica claramente que el mecanismo funciona y que la Corte está ejerciendo sus funciones como tribunal constitucional. Prueba de ello es que el número de acciones se ha venido incrementando de manera muy

47 http://www.cide.edu/investigador/sitios.php? IdInvestigador=1079. 
significativa en los últimos años, al punto que en una estimación realizado por la Dirección General de Planeación de lo Jurídico de la propia Suprema Corte de Justicia, se calcula que para 2010 se recibirán alrededor de 342 acciones (mínimo 167 - máximo 517). Este número contrasta con los datos de los primeros años de vida de este instrumento en que, por lo menos hasta 2006, no se rebasaban las 50 acciones interpuestas por año. La siguiente gráfica sintetiza esta tendencia.

Gráfica 2. Ingreso de acciones de inconstitucionalidad (1995-2007) y proyección 2008-2010

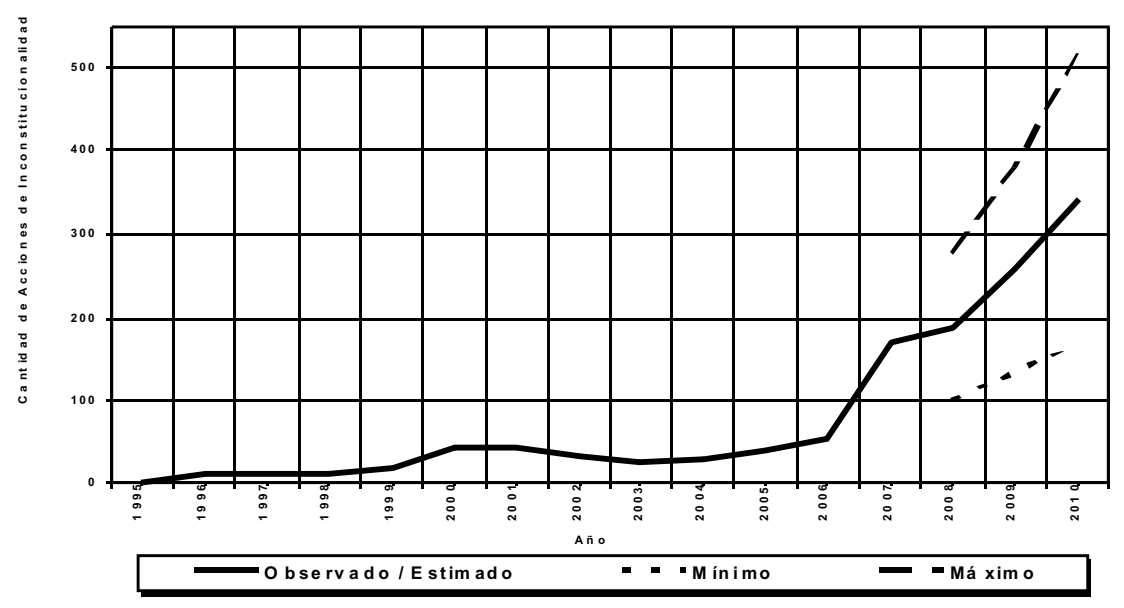

Fuente: Dirección General de Planeación de lo Jurídico de la Suprema Corte de Justicia de la Nación.

¿Cuáles son las consecuencias de estas tendencias para la vida institucional de la Corte? Para evaluarlas en su justa dimensión conviene recordar cómo se conformó la carga de trabajo total de la Corte. Los datos muestran que, respecto de la novena época, es decir de enero de 1995 a diciembre de 2007, la corte atendió un total de 46,093 asuntos, de los cuales 20,801 fueron amparos directos en revisión, 23,584 amparos en revisión, 1,220 controversias constitucionales y 488 acciones de incons- 
titucionalidad. ${ }^{48}$ Como puede observarse, el grueso de la carga de trabajo se concentra en los amparos, es decir, principalmente en el análisis de problemas de legalidad. Sin embargo, si se observa el crecimiento exponencial de las acciones de inconstitucionalidad y las controversias constitucionales y está tendencia se confirma, es claro que la función de la Suprema Corte se está modificando para convertirse cada vez más, como era la intención de la reforma, en un auténtico tribunal constitucional. Por ello conviene reflexionar sobre la conveniencia de limitar aún más la carga de trabajo de la carga en materia de amparo para limitarlo a las auténticas cuestiones de control de constitucionalidad e ir consolidando su papel de garante de la Constitución.

Desde otra perspectiva, los datos muestran una tendencia gradual pero definida de especialización en el litigio constitucional. Este ha crecido no sólo en el número de acciones, sino también en la complejidad e importancia de las materias controvertidas. El análisis de las más recientes acciones de inconstitucionalidad muestran claramente que cada vez más se promueven asuntos de autentica relevancia constitucional. Ello supone una especialización relativa de los actores (cada vez son menos las acciones de machote o aquellas que muestran una limitada comprensión del mecanismo) y una creciente complejidad técnica. Asimismo existen indicios de un mayor equipamiento institucional para el litigio constitucional (por ejemplo al interior de la Procuraduría General de la República), más abogados capaces de desarrollar esta actividad e incluso el desarrollo del derecho procesal constitucional como una disciplina especializada.

Quizá esto prueba que, con el tiempo, estamos lenta pero efectivamente transitando de un paradigma autoritario a otro que privilegia el Estado de derecho y su autonomía; de un modelo de comportamiento social cuyas expectativas se basaban en intereses, favores, evasión de la ley y de uso de la negociación y la presión como mecanismo para obtener resultados, a otro que privilegia la reivindicación de los derechos, el uso de los procedimientos jurídicos para hacer valer las reclamaciones y la legalidad. ${ }^{49}$ Como hemos afirmado previamente, la autonomía del derecho y

48 Datos proporcionados por la Dirección General de Planeación de lo Jurídico de la Suprema Corte de Justicia de la Nación.

49 Sobre la idea de transición jurídica y una explicación de sus paradigmas véase Fix-Fierro, Héctor y Sergio López-Ayllón, "Cambio jurídico y autonomía del derecho: un modelo de la transición jurídica en México”, en Serna de la Garza, José María y Ca- 
sus instituciones es un proceso lento y de difícil aprendizaje para una sociedad, "pero sólo las sociedades que son capaces de lograrlo pueden esperar que su sistema jurídico le abra las puertas a grados crecientes de complejidad, variedad, individualidad, certidumbre y ocasionalmente justicia". ${ }^{0}$

Finalmente, el estudio muestra que los ajustes necesarios en materia de acciones son realmente menores. Algunas de las propuestas específicas, por ejemplo la modificación de la exigencia de contar con una mayoría calificada para asegurar que la sentencia tenga efectos generales; la modificación de los plazos para interponer y resolver las acciones o la codificación de los procedimientos de justicia constitucional en un solo Código no parecen, a la luz de los resultados de este estudio, como condiciones indispensables para un mejor funcionamiento sustancial de la acción de inconstitucionalidad.51 Quizá se requiere considerar la posibilidad de suspender la vigencia de disposiciones generales; mejorar los tiempos de resolución en materia de disposiciones con una vigencia limitada, especialmente en materia fiscal; crear reglas de mayor transparencia en este tipo de acciones o permitir una más activa participación de los actores sociales a través del amicus curiae. ${ }^{52}$ Estas ideas, aunque suponen mejoras importantes, resultan relativamente marginales en un cauce que en general parece avanzar en la dirección correcta. Quizá el avance mayor esté en la auténtica comprensión del significado del Estado constitucional de derecho y en el fortalecimiento de la Corte como un auténtico tribunal constitucional.

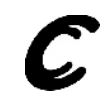

ballero, Antonio (eds.), Estado de derecho y transición jurídica, México, UNAM, Instituto de Investigaciones Jurídicas, 2002, pp. 95-137.

50 Ibidem, p. 137.

51 Sobre las propuestas de reformas véase Caballero, José Antonio et al., op cit., nota 1 , pp. 153-157.

52 Un ejemplo notable de estas prácticas, y que por cierto no requirieron de cambios constitucionales o legales, se dio en el caso de las acciones de inconstitucionalidad 146/2007 y 147/2007 relativas a la despenalización del aborto en el Distrito Federal. Muy especialmente debe considerarse la celebración de audiencias públicas en donde los ministros escucharon las diversas posiciones sobre el tema y la creación de un micrositio en la página de Internet de la SCJN donde se presentó información de gran calidad sobre este procedimiento y abrió un canal de información y comunicación que permitió la participación de muchos y una mejor comprensión de la labor de la Suprema Corte. El micrositio puede aún consultarse en la página www.scjn.gob.mx. 